$\begin{array}{ll}\text { Research Square } & \begin{array}{l}\text { Preprints are preliminary reports that have not undergone peer review. } \\ \text { They should not be considered conclusive, used to inform clinical practice, } \\ \text { or referenced by the media as validated information. }\end{array}\end{array}$

\title{
In vivo monoclonal antibody efficacy against SARS-CoV-2 variant strains
}

Michael Diamond ( $\square$ mdiamond@wustl.edu)

Washington University School of Medicine https://orcid.org/0000-0002-8791-3165

Rita Chen

Washington University School of Medicine

Emma Winkler

Washington University in St. Louis

James Case

Washington University School of Medicine https://orcid.org/0000-0001-7331-5511

Ishmael Aziati

Washington University School of Medicine

Traci Bricker

Washington University School of Medicine

Astha Joshi

Washington University School of Medicine

Tamarand Darling

Washington University School of Medicine

Baoling Ying

Washington University School of Medicine

John Errico

Washington University

Swathi Shrihari

Washington University School of Medicine

Laura VanBlargan

Washington University

Xuping Xie

University of Texas Medical Branch https://orcid.org/0000-0003-0918-016X

Pavlo Gilchuk

Vanderbilt University Medical Center

Seth Zost

Vanderbilt University Medical Center https://orcid.org/0000-0001-6712-5076

Lindsay Droit

Washington University School of Medicine

Zhuoming Liu

Washington University School of Medicine https://orcid.org/0000-0001-8198-0976

Spencer Stumpf

Washington University

David Wang

Washington University in St. Louis

Scott Handley

Washington University

W Stine

AbbVie

Pei-Yong Shi

The University of Texas Medical Branch at Galveston https://orcid.org/0000-0001-5553-1616

Miguel Garcia-Knight

University of California, San Francisco

Raul Andino

University of California, San Francisco https://orcid.org/0000-0001-5503-9349

Charles Chiu

University of California, San Francisco https://orcid.org/0000-0003-2915-2094

Ali Ellebedy

Washington University School of Medicine https://orcid.org/0000-0002-6129-2532

Daved Fremont 
Washington University School of Medicine https://orcid.org/0000-0002-8544-2689

Sean Whelan

Washington University in Saint Louis https://orcid.org/0000-0003-1564-8590

James Crowe

Vanderbilt University Medical Center https://orcid.org/0000-0002-0049-1079

Lisa Purcell

Vir Biotechnology, Washington University School of Medicine

Davide Corti

Vir Biotechnology, Washington University School of Medicine https://orcid.org/0000-0002-5797-1364

Andrianus Boon

Washington University School of Medicine https://orcid.org/0000-0002-4700-8224

\section{Biological Sciences - Article}

Keywords: SARS-CoV-2 variant strains, variations, antibodies

Posted Date: April 23rd, 2021

DOI: https://doi.org/10.21203/rs.3.rs-448370/v1

License: () (7) This work is licensed under a Creative Commons Attribution 4.0 International License. Read Full License

Version of Record: A version of this preprint was published at Nature on June 21st, 2021. See the published version at https://doi.org/10.1038/s41586-02103720-y. 


\section{Abstract}

Rapidly-emerging variants jeopardize antibody-based countermeasures against SARS-CoV-2. While recent cell culture experiments have demonstrated loss of potency of several anti-spike neutralizing antibodies against SARS-CoV-2 variant strains1-3, the in vivo significance of these results remains uncertain. Here, using a panel of monoclonal antibodies (mAbs) corresponding to many in advanced clinical development by Vir Biotechnology, AbbVie, AstraZeneca, Regeneron, and Lilly we report the impact on protection in animals against authentic SARS-CoV-2 variants including WA1/2020 strains, a B.1.1.7 isolate, and chimeric strains with South African (B.1.351) or Brazilian (B.1.1.28) spike genes. Although some individual mAbs showed reduced or abrogated neutralizing activity against B.1.351 and B.1.1.28 viruses with E484K spike protein mutations in cell culture, low prophylactic doses of mAb combinations protected against infection in K18-hACE2 transgenic mice, 129S2 immunocompetent mice, and hamsters without emergence of resistance. Two exceptions were mAb LY-CoV555 monotherapy which lost all protective activity in vivo, and AbbVie 2B04/47D11, which showed partial loss of activity. When administered after infection as therapy, higher doses of mAb cocktails protected in vivo against viruses displaying a B.1.351 spike gene. Thus, many, but not all, of the antibody products with Emergency Use Authorization should retain substantial efficacy against the prevailing SARS-CoV-2 variant strains.

\section{Introduction}

Severe acute respiratory syndrome coronavirus 2 (SARS-CoV-2) has caused the global coronavirus disease 2019 (COVID-19) pandemic and resulted in more than 140 million confirmed infections and over 3 million deaths. The sustained nature of the COVID-19 pandemic and its accompanying extensive morbidity and mortality have made the development and immediate deployment of therapeutics and vaccines an urgent global health priority ${ }^{4}$. Indeed, the emergency use authorization (EUA) of several monoclonal antibody (mAb) therapies and mRNA, inactivated, and viral-vectored vaccines has provided hope for controlling infection and curtailing the pandemic.

Currently authorized antibody countermeasures against SARS-CoV-2 target the spike protein from strains circulating during the early phases of the pandemic in 2020. The SARS-CoV-2 spike protein binds the cell-surface receptor angiotensin-converting enzyme 2 (ACE2) to facilitate viral entry into and infection of human cells ${ }^{5}$. Upon cell attachment, SARS-CoV-2 spike proteins are cleaved by host proteases into S1 and S2 fragments. The S1 protein includes the Nterminal (NTD) and receptor binding (RBD) domains, whereas the $\mathrm{S} 2$ protein promotes membrane fusion. The RBD, in particular, is the target of many potently neutralizing monoclonal ${ }^{6-10}$ and serum polyclonal antibodies ${ }^{11}$.

Over the past several months, SARS-CoV-2 variant strains have emerged in the United Kingdom (B.1.1.7), South Africa (B.1.351), Brazil (B.1.1.28 [also called P.1]) and elsewhere containing substitutions in the spike protein in the NTD and the receptor binding motif (RBM) of the RBD. Experiments with pseudoviruses and authentic infectious SARS-CoV-2 strains suggest that neutralization by a substantial fraction of previously generated antibodies may be diminished against variants expressing mutations in the spike gene, especially at position E484 ${ }^{1-3,12,13}$. However, the in vivo significance of this loss of mAb neutralizing activity remains uncertain, particularly for combination mAb therapies, as high doses could compensate for changes in neutralization potency. Here, using mice and hamsters, we assessed the protective activity of clinically relevant mAbs against WA1/2020 strains and a panel of SARS-CoV-2 variants including a B.1.1.7 isolate, and chimeric strains with South African (B.1.351) or Brazilian (B.1.1.28) spike genes. We tested cocktails of mAbs from AbbVie (2B04/47D11) and Vir Biotechnology (S309/S2E12) as well as ones corresponding to those from AstraZeneca (COV2-2130/COV2-2196), Regeneron (REGN10933/REGN10987), and Lilly (LY-CoV555) as prophylaxis or therapy against SARS-CoV-2 in K18-hACE2 transgenic mice, 129S2 immunocompetent mice, and Syrian hamsters. Whereas several antibody combinations conferred protection in both mouse models with all variant strains tested, the 2B04/47D11 combination and LY-CoV555 showed reduced or complete loss of protective activity. One of the combinations (COV2-2130/COV2-2196) also showed equivalent protective activity in hamsters against WA1/2020 D614G and the chimeric strain with a B.1.351 spike.

\section{Results}

To evaluate the effects of SARS-CoV-2 strain variation on mAb protection, we assembled a panel of infectious SARS-CoV-2 strains with sequence substitutions in the spike gene (Fig 1a-b). A B.1.1.7 isolate from the United Kingdom had signature changes in the spike gene ${ }^{14}$ including the $69-70$ and $144-$ 145 deletions, and N501Y, A570D, D614G, and P681H substitutions. A B.1.429 isolate from California contained the characteristic S13I, W152C, and L452R changes. We also used a previously generated Washington SARS-CoV-2 strain with a D614G substitution (WA1/2020 D614G), a SARS-CoV-2 strain with N501Y and D614G substitutions (WA1/2020 N501Y/D614G), and recombinant, chimeric SARS-CoV-2 strains with a South African (Wash SA-B.1.351; D80A, D215G, 242-244 deletion, K417N, E484K, N501Y, D614G, and A701V) or Brazilian (Wash BR-B.1.1.28; L18F, T20N, P26S, D138Y, R190S, K417T, E484K, N501Y, D614G, H655Y, T1027l, and V1176F) spike genes in the Washington strain background ${ }^{1,15}$. All viruses were propagated in Vero cells expressing transmembrane protease serine 2 (TMPRSS2) to prevent the emergence of mutations at or near the furin cleavage site in the spike protein, which occurs with passage in Vero $\mathrm{E} 6$ cells ${ }^{16}$ and can impact virulence ${ }^{17}$. All viruses were deep-sequenced to confirm the presence of expected mutations prior to use in vitro or in vivo (Supplementary Table S1).

We first assessed the impact of SARS-CoV-2 spike variation on antibody neutralization in Vero-TMPRSS2 cells (Fig 1c-d) using the WA1/2020 D614G, WA1/2020 N501Y/D614G, B.1.1.7, Wash SA-B.1.351, Wash BR-B.1.1.28, and B.1.429 viruses. We tested individual and cocktails of mAbs in clinical development that target the RBD including 2B04/47D11 (AbbVie), S309/S2E12 (Vir Biotechnology), COV2-2130/COV2-2196 (Vanderbilt University Medical Center with engineered derivatives being evaluated by AstraZeneca), REGN10933/REGN10987 (synthesized based on casirivimab and imdevimab sequences from Regeneron), and LY-CoV555 (synthesized based on bamlanivimab sequences from Lilly). All individual mAbs tested efficiently neutralized the WA1/2020 D614G, WA1/2020 N501Y/D614G, and B.1.1.7 strains, and several mAbs (COV2-2130, COV2-2196, S309, S2E12, and 47D11) showed little change in potency against the Wash SA-B.1.351, Wash BR-B.1.1.28, and B.1.429 strains (Fig 1c-d). In comparison, REGN10987 or LY-CoV555 respectively showed a 10-fold or complete loss in inhibitory activity against the B.1.429 strain, which is consistent with studies identifying L452 and adjacent residues as interaction sites for 
these mAbs (Table 1). Moreover, REGN10933, LY-CoV555, and 2B04 exhibited a marked loss or complete absence of neutralizing activity against Wash SAB.1.351, Wash BR-B.1.1.28, and viruses containing the E484K mutation (Fig 10-d and Extended Data Fig 1), which corresponds with structural and mapping studies (Table 1). Analysis of mAb cocktails showed that COV2-2130/COV2-2196, S309/S2E12, and REGN10933/REGN10987 neutralized all virus strains tested, with the latter combination retaining potency corresponding to the mAb with inhibitory activity in the cocktail for a given virus. In comparison, while the 2B04/47D11 mAb combination efficiently neutralized WA1/2020 D614G, WA1/2020 N501Y/D614G, B.1.1.7, and B.1.429 strains, its inhibitory activity against Wash SA-B.1.351 and Wash BR-B.1.1.28 reflected the less potent 47D11 mAb component (EC ${ }_{50}$ of $\left.384-431 \mathrm{ng} / \mathrm{mL}\right)(\mathrm{Fig} 1 \mathrm{c}-\mathrm{d})$.

To evaluate the efficacy of the mAb combinations in vivo, we initially used the K18-hACE2 transgenic mouse model of SARS-CoV-2 pathogenesis in which human ACE2 expression is driven by the cytokeratin-18 gene promoter ${ }^{18,19}$. In prior studies, we established that low $(2 \mathrm{mg} / \mathrm{kg})$ doses of several different antiRBD neutralizing human mAbs provide a threshold of protection against the WA1/2020 strain when administered as prophylaxis ${ }^{20}$. Accordingly, we gave K18hACE2 mice a single 40 gg ( 2 mg/kg total) dose of mAb combinations (2B04/47D11, S309/S2E12, COV2-2130/COV2-2196, or REGN10933/REGN10987) or LY-CoV555 as monotherapy by intraperitoneal injection one day prior to intranasal inoculation with SARS-CoV-2 (10 ${ }^{3}$ focus-forming units [FFU] of WA1/2020 N501Y/D614G, B.1.1.7, Wash SA-B.1.351 or Wash BR-B.1.1.28). For these in vivo studies, we used a recombinant version of WA1/2020 that encodes N501Y for direct comparison to B.1.1.7, Wash SA-B.1.351 or Wash BR-B.1.1.28, all of which naturally contain this residue. This substitution increases infection and pathogenicity in mice 21,22 yet did not substantively impact neutralization of the mAbs we tested (Fig 1c). We monitored weight change for six days, and then euthanized animals and harvested tissues for virological and immunological analyses.

Compared to a control human mAb (anti-West Nile virus $\mathrm{hE} 16^{23}$ ), a single $40 \mathrm{mg}$ prophylaxis dose of the anti-SARS-CoV-2 mAbs conferred substantial protection against WA1/2020 N501Y/D614G-induced weight loss and viral burden in the lungs, nasal washes, brain, spleen, and heart in the K18-hACE2 mice at 6 days post-infection (dpi) (Fig 2a-d, Extended Data Fig 2 and 3a). While all of the anti-SARS-CoV-2 mAb cocktails conferred protection against weight loss caused by B.1.1.7, Wash SA-B.1.351 or Wash BR-B.1.1.28, LY-CoV555 monotherapy protected only against the B.1.1.7 strain (Fig 2e, i, and $\mathrm{m}$ ). Some of the antibodies provided less virological protection against the B.1.1.7, Wash SA-B.1.351 or Wash BR-B.1.1.28 strains in specific tissues. Whereas all mAb groups protected against B.1.1.7 infection in the lung, 2B04/47D11 and LY-CoV555 failed to perform as well in nasal washes, and LY-CoV555 showed reduced protection against infection in the brain (Fig 2f-h). Sanger sequencing analysis of the RBD region of viral RNA of brain, nasal wash, and lung samples from animals treated with these mAbs did not show evidence of neutralization escape (Supplementary Table S2). 2B04/47D11 and LY-CoV555-treated animals also showed greater virus breakthrough than the other tested antibodies when challenged with Wash SA-B.1.351 or Wash BR-B.1.1.28 viruses: 2B04/47D11 reduced viral burden in the lungs, nasal washes, and brain (500-10,000-fold) much less efficiently than other mAb cocktails, and LY-CoV555 mAb treatment conferred virtually no virological protection in any tissue analyzed (Fig 2j-l and n-p and Extended Data Fig 3b). Compared to the COV2-2130/COV2-2196 and S309/S2E12 combinations, REGN10933/REGN10987 also showed less ability to reduce viral RNA levels in nasal washes of K18-hACE2 mice infected with Wash SA-B.1.351 or Wash BR-B.1.1.28 viruses.

An excessive pro-inflammatory host response to SARS-CoV-2 infection is hypothesized to contribute to pulmonary pathology and severe COVID-1924. To evaluate further the extent of protection conferred by the different mAb groups against the SARS-COV-2 variant viruses, we measured pro-inflammatory cytokine and chemokines in lung homogenates harvested at 6 dpi (Fig 2q and Extended Data Fig 4). This analysis showed a strong correspondence with viral RNA levels in the lung: (a) compared to the control mAb, S309/S2E12, COV2-2130/COV2-2196, and REGN10933/REGN10987 combinations showed markedly reduced levels of pro-inflammatory cytokines and chemokines (G-CSF, IFN-g, IL-6, CXCL10, LIF, CCL2, CXCL9, CCL3, and CCL4) after infection with WA1/2020 N501Y/D614G, B.1.1.7, Wash SA-B.1.351 or Wash BR-B.1.1.28; (b) prophylaxis with 2B04/47D11 or LY-CoV555 resulted in reduced inflammatory cytokine and chemokine levels in mice infected with WA1/2020 N501Y/D614G and B.1.1.7, with substantially less improvement in animals infected with Wash SA-B.1.351 and Wash BR-B.1.1.28.

Given that a 40 mg dose of S309/S2E12, COV2-2130/COV2-2196, and REGN10933/REGN10987 combinations prevented infection and inflammation caused by the different SARS-CoV-2 strains, we next tested a ten-fold lower $4 \mathrm{mg}$ dose $(\sim 0.2 \mathrm{mg} / \mathrm{kg})$ to assess for possible differences in protection. Prophylaxis with COV2-2130/COV2-2196, S309/S2E12, REGN10933/REGN10987, or 2B04/47D11 protected K18-hACE2 mice against weight loss caused by all four viruses (Extended Data Fig 5a-d). Whereas the COV2-2130/COV2-2196, S309/S2E12, and REGN10933/REGN10987 mAb combinations reduced viral RNA levels in the lung at 6 dpi in K18-hACE2 mice infected with WA1/2020 N501Y/D614G, B.1.1.7, Wash SA-B.1.351, or Wash BR-B.1.1.28, the 2B04/47D11 treatment conferred protection against B.1.1.7 and WA1/2020 N501Y/D614G but not against Wash SA-B.1.351 and Wash BR-B.1.1.28 viruses at this lower dose (Extended Data Fig 5e-h). In comparison, in nasal washes, all four mAb cocktails resulted in relatively similar reductions in viral RNA levels at 6 dpi of animals inoculated with WA1/2020 N501Y/D614G, B.1.1.7, Wash SA-B.1.351 or Wash BR-B.1.1.28 (Extended Data Fig 5i-I). Even at this low treatment dose, with the exception of some substantive breakthrough events (>6 log 10 copies of N/mg: COV2-2130/COV2-2196 [2 of 24 mice]; S309/S2E12 [6 of 24 mice]; REGN10933/REGN10987 [1 of 24 mice]; and 2B04/47D11 [6 of 24 mice]), the mAb combinations generally prevented viral dissemination to and high-level infection of the brain (Extended

\section{Data Fig 5m-p and Supplementary Table S2).}

Although K18-hACE2 mice have been used extensively to test vaccines and therapeutics against SARS-CoV- $2^{20,25-28}$, the high level and distinct pattern of transgene expression in these animals could impact entry pathways, and neutralization and protection conferred by anti-RBD antibodies. As an alternative model for evaluating mAb efficacy, we tested immunocompetent, inbred $129 \mathrm{~S} 2$ mice, which are permissive to infection by SARS-CoV-2 strains encoding an N501Y substitution without ectopic hACE2 expression ${ }^{21,22}$; presumably, the N501Y adaptive mutation enables efficient engagement of murine (m)ACE2. We administered a single $40 \mu \mathrm{g}(\sim 2 \mathrm{mg} / \mathrm{kg}$ ) dose of mAb cocktails (COV2-2130/COV2-2196, S309/S2E12, or REGN10933/REGN10987) or a control mAb via intraperitoneal injection one day prior to intranasal inoculation with $10^{3}$ FFU of WA1/2020 N501Y/D614G, Wash SA-B.1.351, or Wash BR-B.1.1.28, and 10 5 FFU of B.1.1.7 (Fig 3). A higher inoculating dose of B.1.1.7 was required to obtain equivalent levels of viral RNA in the lung compared to the other three viruses. At $3 \mathrm{dpi}$, we harvested tissues for viral burden analyses; at this time point, reproducible weight loss was not observed. All three mAb cocktails tested (COV22130/COV2-2196, S309/S2E12, and REGN10933/REGN10987) protected 129S2 mice against infection in the lung by all SARS-CoV-2 strains as judged by 
reductions in viral RNA levels (Fig 3a-d); despite some variability, we observed a trend toward less complete protection in animals infected with Wash SAB.1.351 and Wash BR-B.1.1.28 strains (Fig 3c-d and Extended Data Fig 3c-f). When we evaluated the nasal washes, reductions in viral RNA levels were diminished with the Wash SA-B.1.351 virus, especially for the COV2-2130/COV2-2196 and REGN10933/REGN10987 combinations (Fig 3e-h). Sequencing analysis of lung samples from the infected 129S2 mice also did not reveal evidence of acquisition of mutations in the RBD (Supplementary Table S2).

The immunocompetent Syrian golden hamster also has been used to evaluate mAb activity against SARS-CoV-2 infection in the upper and lower respiratory tracts $^{29,30}$. We used this animal model to assess independently the inhibitory activity and possible emergence of resistance of one of the mAb combinations (COV2-2130/COV2-2196) against viruses containing the B.1.351 spike protein at threshold doses of protection. One day prior to intranasal inoculation with $5 \mathrm{x}$ $10^{5} \mathrm{FFU}$ of Wash SA-B.1.351 or WA1/2020 D614G, we treated hamsters with a single $800 \mu \mathrm{g}(\sim 10 \mathrm{mg} / \mathrm{kg})$ or $320 \mu \mathrm{gg}(\sim 4 \mathrm{mg} / \mathrm{kg}) \mathrm{dose}$ of the COV22130/COV2-2196 cocktail or isotype control mAb by intraperitoneal injection (Fig 4). Weights were followed for 4 days, and then tissues were harvested for virological and cytokine analysis. At the $800 \mu \mathrm{g}$ mAb cocktail dose, hamsters treated with COV2-2130/COV2-2196 and infected with WA1/2020 D614G or Wash SA-B.1.351 showed protection against weight loss (Fig 4a) and reduced viral burden levels in the lungs but not nasal swabs compared to the isotype control mAb (Fig 4b-d). Correspondingly, RT-qPCR analysis of a previously described set of cytokines and inflammatory genes ${ }^{20}$ showed reduced mRNA expression in the lungs of hamsters treated with COV2-2130/COV2-2196 (Fig 4e-h). Consensus sequencing of the RBD region of viral RNA samples from the lungs of hamsters treated with COV2-2130/COV2-2196 and inoculated with WA1/2020 D614G or Wash SA-B.1.351 did not show evidence of mutation or escape (Supplementary Table S2). When the lower $320 \mu \mathrm{g}$ dose of COV2-2130/COV2-2196 was administered, we observed a trend toward protection against weight loss in hamsters infected with WA1/2020 D614G and Wash SA-B.1.351 (Fig 4i). Consistent with a partially protective phenotype, hamsters treated with the lower $320 \mu \mathrm{g}$ dose of COV2-2130/COV2-2196 and inoculated with either WA1/2020 D614G and Wash SA-B.1.351 showed a trend towards reduced viral RNA in the lungs at $4 \mathrm{dpi}$ and markedly diminished ( $10^{4}$ to $10^{5}$-fold) levels of infectious virus as determined by plaque assay (Fig $4 \mathrm{j}-\mathbf{k}$ ). The reduction in lung viral load conferred by the lower dose COV2-2130/COV2-2196 corresponded with diminished inflammatory gene expression after infection with either WA1/2020 D614G or Wash SA-B.1.351 (Fig 4m-p). In contrast to the protection seen in the lung, differences in viral RNA were not observed in nasal washes between COV2-2130/COV2-2196 and isotype control mAb-treated animals regardless of the infecting strain (Fig 4I). Sequencing of the RBD of viral RNA from the lungs of COV2-2130/COV2-2196 or isotype mAb-treated hamsters also did not detect evidence of escape mutation selection after infection with WA1/2020 D614G or Wash SA-B.1.351 (Supplementary Table S2). Overall, these studies in hamsters with near threshold dosing of the COV2-2130/COV2-2196 mAb cocktail establish equivalent protection and an absence of rapid escape against SARS-CoV-2 containing spike proteins from historical or variant strains.

As mAbs are being developed clinically as therapeutics, we assessed their post-exposure efficacy against the SARS-CoV-2 strain expressing the B.1.351 spike protein using the stringent K18-hACE2 model. We administered a single, higher $200 \mu \mathrm{g}(\sim 10 \mathrm{mg} / \mathrm{kg})$ dose of COV2-2130/COV2-2196, S309/S2E12,

REGN10933/REGN10987 or 2B04/47D11 by intraperitoneal injection one day after inoculation with 103 FFU of WA1/2020 N501Y/D614G or Wash SA-B.1.351, and then monitored the mice for six days prior to necropsy and virological analysis (Fig 5). We did not test the LY-CoV555 mAb in these therapeutic experiments, since it failed to protect against Wash SA-B.1.351 as prophylaxis. Compared to the control mAb-treated animals, which lost at least $15 \%$ of their starting weight over the 6 days of the experiment, each of the mAb cocktails prevented weight loss induced by WA1/2020 N501Y/D614G or Wash SA-B.1.351 infection (Fig 5a and e). COV2-2130/COV2-2196, S309/S2E12, and REGN10933/REGN10987 mAb cocktail treatments resulted in reduced infectious virus and viral RNA levels in lung homogenates, and viral RNA levels in nasal washes and brain homogenates from animals infected with either WA1/2020

N501Y/D614G or Wash SA-B.1.351 (Fig 5b-d, f-h and Extended Data Fig 3g-h). In comparison, while the 2B04/47D11 mAb cocktail reduced viral RNA levels in the lungs, it showed less protection in the nasal washes of WA1/2020 N501Y/D614G and Wash SA-B.1.351 infected mice.

\section{Discussion}

With the emergence of several SARS-CoV-2 variants, it remains uncertain whether currently developed vaccines and antibody-based therapies will lose efficacy ${ }^{31}$. Many of the mutations and deletions in the spike proteins of variant strains occur in the N-terminal domain and the RBD, including within or proximal to the hACE2 receptor binding motif. Cell-culture based studies have shown that several of these mutations, especially those at positions 452 and 484 , reduce neutralization capacity of monoclonal and serum antibodies derived from naturally infected or vaccinated individuals ${ }^{1-3,32,33}$. Here we evaluated antibodies forming the basis of five different $\mathrm{mAb}$ therapies in clinical development for in vivo efficacy against infection by SARS-CoV-2 variants including a B.1.1.7 isolate and chimeric strains with B.1.351 or B.1.1.28 spike genes. Monotherapy with LY-CoV555, an antibody corresponding to bamlanivimab34, showed complete neutralization escape in cell culture and failed to confer any protection against viruses containing E484K substitutions. In contrast, all cocktails of two neutralizing $m A$ bs conferred protection to varying degrees even if one of the constituent mAbs showed reduced activity due to resistance. Moreover, the higher doses of mAbs used in patients (e.g., $2.4 \mathrm{~g}$ or $~ 35 \mathrm{mg} / \mathrm{kg}$ for casirivimab and imdevimab [REGN mAbs]) could compensate for loss in neutralization potency.

Combination therapy with multiple mAbs in our study (COV2-2130/COV2-2196, S309/S2E12, REGN10933/REGN10987, or 2B04/47D11) was protective in mice and hamsters against the variant strains, highlighting the importance of using multiple mAbs recognizing distinct epitopes rather than monotherapy to control SARS-CoV-2 infection. Indeed, the emergency use authorization for bamlanivimab (LY-CoV555) as monotherapy recently was revoked, since the antibody does not efficiently reduce SARS-CoV-2 infection of several variants of concern that are spreading globally 35 ; instead, a combination of bamlanivimab and etesevimab is now recommended even though some strains containing E484 and K417 mutations (e.g., B.1.351 and B.1.1.28) likely will have resistance to both $\mathrm{mAb}$ components (2,36 and Extended Data Fig 6). In our study, combination therapy with two mAbs including one (2B04) that failed to neutralize a virus containing the E484K mutation still protected when administered at higher doses, although the reduction in viral burden was less than with other mAb cocktails at equivalent doses. Beyond a loss of potency against already circulating resistant variants, antibody monotherapy can be compromised within an individual by rapid selection of escape mutations de novo or enrichment of pre-existing mutants in the quasispecies present at low frequency. Consistent with this idea, in other animal experiments with SARS-CoV-2, we have observed the rapid emergence of resistance against antibody monotherapy, resulting in the accumulation of mutations at RBD residues 476,477484 , and 487 , only some of which were detectable in our parental virus stocks by next

Page 5/17 
generation sequencing ( ${ }^{37}$ and M. Diamond, A. Boon, and A. Ellebedy, unpublished data). Remarkably, and despite amplifying the RBD sequence from 96 brain, nasal wash, and lung samples from mice and hamsters treated with the different mAb combinations, we did not detect a single escape mutant. Although further study is warranted, combination mAb treatment may prevent escape through synergistic interactions in vivo or by driving selection of mutants with compromised fitness.

At the lower doses of mAbs tested, we observed some differences in mAb cocktail efficacy between rodent models, which could be due to host variation, viral variation, or both. For example, mutations in the RBD can affect mAb binding as well as ACE2 binding ${ }^{38}$. Mutation at position 501 of the spike is of particular interest, since it enables mouse adaptation ${ }^{21,22}$ and is present in many variants of concern (e.g., B.1.1.7, B.1.351, and B.1.1.28). The N501Y change associated with infection of conventional laboratory mice could facilitate virus engagement with murine ACE2 or possibly other putative target receptors ${ }^{39}$. Beyond this, polymorphisms in or differences of expression of host receptors on key target cells also could impact SARS-CoV-2 infection in different hosts and the inhibitory effects of neutralizing antibodies. As both viral and host sequences determine the interface between SARS-CoV-2 spike and its cell entry receptors like ACE2, mAb interactions and potency could be affected in different species of animals. Changes in the affinity of interaction between spike proteins and receptors can impact the stoichiometry of neutralizing antibody binding required to inhibit infection ${ }^{40}$. Although further study of antibody-based countermeasures in vivo is required, the complexity of antibody-spike protein-receptor interactions likely explains some of the variation in protection K18hACE2 mice, 129S2 mice, and hamsters. Alternatively, the pharmacokinetics and/or biodistribution of antibodies in these animals also could vary and affect efficacy. In the animal models we tested, we did not observe marked differences in serum antibody levels in the context of viral challenge (Supplementary Table S3).

Cell culture-based analyses of individual neutralizing antibodies in clinical development with pseudoviruses and authentic SARS-CoV-2 containing substitutions corresponding to those in circulating variants suggested that adjustments to therapeutic antibody regimens might be necessary to maintain efficacy ${ }^{1,2,41-43}$. Although our in vivo studies with several SARS-CoV-2 variant strains in multiple rodent models suggest this conclusion likely holds for mAb monotherapy, four different mAb combinations performed remarkably well even when a particular variant containing an E484K mutation was fully resistant to one mAb component, as rapid escape over the short time course of study was not observed in nasal washes or lung tissues. While corroborative analysis of antibody efficacy in non-human primates and humans is needed, especially under conditions of protracted infection or high viral burden, our results suggest that, as described previously with the historical WA1/2020 strain ${ }^{44}$, combination therapy with neutralizing mAbs may retain efficacy against emerging SARSCoV-2 variants and limit the development of resistance.

\section{Methods}

Cells. Vero-TMPRSS2 cells ${ }^{46}$ and Vero-hACE2-TMPRSS2 (gift of A. Creanga and B. Graham, NIH, Bethesda, MD) cells were cultured at $37^{\circ} \mathrm{C}$ in Dulbecco's Modified Eagle medium (DMEM) supplemented with 10\% fetal bovine serum (FBS), 10 mM HEPES pH 7.3, 1 mM sodium pyruvate, $1 \times$ non-essential amino acids, and $100 \mathrm{U} / \mathrm{ml}$ of penicillin-streptomycin. Vero-TMPRSS2 cells were supplemented with $5 \mathrm{mg} / \mathrm{mL}$ of blasticidin and Vero-hACE2-TMPRSS2 cells were supplemented with $10 \mu \mathrm{g} / \mathrm{mL}$ of puromycin.

Viruses. The WA1/2020 recombinant strain with substitutions (D614G or N501Y/D614G) were obtained from an infectious cDNA clone of the 2019nCoV/USA_WA1/2020 strain as described previously ${ }^{47}$. The South African (B.1.351) and Brazilian (B.1.1.28) variant spike genes were introduced into the WA1/2020 backbone as described previously ${ }^{1}$. The B.1.1.7 and B.1.429 isolates were obtained from nasopharyngeal isolates. All viruses were passaged once in Vero-TMPRSS2 cells and subjected to next-generation sequencing as described previously ${ }^{1}$ to confirm the introduction and stability of substitutions (Supplementary Table S1). All virus experiments were performed in an approved biosafety level 3 (BSL-3) facility.

Monoclonal antibody purification. The mAbs studied in this paper (COV2-2196, COV2-2130, S309, S2E12, 2B04, 47D11, REGN10933, REGN10987, LY-CoV555, and CB6) have been described previously 6,8,10,44,48-51. COV2-2196 and COV2-2130 mAbs were produced after transient transfection using the Gibco ExpiCHO Expression System (ThermoFisher Scientific) following the manufacturer's protocol. Culture supernatants were purified using HiTrap MabSelect SuRe columns (Cytiva, formerly GE Healthcare Life Sciences) on an AKTA Pure chromatographer (GE Healthcare Life Sciences). Purified mAbs were buffer-exchanged into PBS, concentrated using Amicon Ultra-4 50-kDa centrifugal filter units (Millipore Sigma) and stored at $-80^{\circ} \mathrm{C}$ until use. Purified mAbs were tested for endotoxin levels (found to be less than $30 \mathrm{EU}$ per $\mathrm{mg} \mathrm{IgG}$ ). Endotoxin testing was performed using the PTS201F cartridge (Charles River), with a sensitivity range from 10 to $0.1 \mathrm{EU}$ per $\mathrm{mL}$, and an Endosafe Nexgen-MCS instrument (Charles River). S309, S2E12, REGN10933, REGN10987, CB6, and LY-CoV555 mAb proteins were produced in CHOEXPI cells and affinity purified using HiTrap Protein A columns (GE Healthcare, HiTrap mAb select Xtra \#28-4082-61). Purified mAbs were suspended into $20 \mathrm{mM}$ histidine, $8 \%$ sucrose, $\mathrm{pH} 6.0$. The final products were sterilized by filtration through $0.22 \mu \mathrm{m}$ filters and stored at $4{ }^{\circ} \mathrm{C}$.

Mouse experiments. Animal studies were carried out in accordance with the recommendations in the Guide for the Care and Use of Laboratory Animals of the National Institutes of Health. The protocols were approved by the Institutional Animal Care and Use Committee at the Washington University School of Medicine (assurance number A3381-01). Virus inoculations were performed under anesthesia that was induced and maintained with ketamine hydrochloride and xylazine, and all efforts were made to minimize animal suffering.

Heterozygous K18-hACE2 C57BL/6J mice (strain: 2B6.Cg-Tg(K18-ACE2)2Prlmn/J) and 129 mice (strain: 129S2/SvPasCrl) were obtained from The Jackson Laboratory and Charles River Laboratories, respectively. Animals were housed in groups and fed standard chow diets. Six- to ten-week-old mice of both sexes were administered $10^{3}$ or $10^{5} \mathrm{FFU}$ of the respective SARS-CoV-2 strain by intranasal administration.

For antibody prophylaxis and therapeutic experiments, animals were administered the indicated mAb dose by intraperitoneal injection one day before or after intranasal inoculation with the indicated SARS-CoV-2 strain. 
Hamster experiments. Six-month-old male Syrian hamsters were purchased from Charles River Laboratories and housed in microisolator units. All hamsters were allowed free access to food and water and cared for under United States Department of Agriculture (USDA) guidelines for laboratory animals. Hamsters were administered by intraperitoneal injection mAbs COV2-2130 + COV2-2196 or isotype control (4 or $10 \mathrm{mg} / \mathrm{kg}$ depending on the experiment). One day later, hamsters were given $5 \times 10^{5} \mathrm{FFU}$ of SARS-CoV-2 (2019-nCoV/USA-WA1/2020) by the intranasal route in a final volume of $100 \mu \mathrm{L}$. All hamsters were monitored for body weight loss until humanely euthanized at $4 \mathrm{dpi}$. Nasal swabs were collected $3 \mathrm{dpi}$. All procedures were approved by the Washington University School of Medicine (assurance number A3381-01). Virus inoculations and antibody transfers were performed under anesthesia that was induced and maintained with $5 \%$ isoflurane. All efforts were made to minimize animal suffering.

Focus reduction neutralization test. Serial dilutions of mAbs (starting at $10 \mathrm{mg} / \mathrm{mL}$ dilution) were incubated with $10^{2}$ focus-forming units (FFU) of different strains or variants of SARS-CoV-2 for $1 \mathrm{~h}$ at $37^{\circ} \mathrm{C}$. Antibody-virus complexes were added to Vero-TMPRSS2 or Vero-hACE2-TMPRSS2 cell monolayers in 96well plates and incubated at $37^{\circ} \mathrm{C}$ for $1 \mathrm{~h}$. Subsequently, cells were overlaid with $1 \%(\mathrm{w} / \mathrm{v}$ ) methylcellulose in MEM supplemented with $2 \%$ FBS. Plates were harvested $24 \mathrm{~h}$ later by removing overlays and fixed with 4\% PFA in PBS for 20 min at room temperature. Plates were washed and sequentially incubated with an oligoclonal pool of SARS2-2, SARS2-11, SARS2-16, SARS2-31, SARS2-38, SARS2-57, and SARS2-71 ${ }^{52}$ anti-S antibodies and HRP-conjugated goat antimouse IgG (Sigma, 12-349) in PBS supplemented with $0.1 \%$ saponin and $0.1 \%$ bovine serum albumin. SARS-CoV-2-infected cell foci were visualized using TrueBlue peroxidase substrate (KPL) and quantitated on an ImmunoSpot microanalyzer (Cellular Technologies).

Measurement of viral burden. Tissues were weighed and homogenized with zirconia beads in a MagNA Lyser instrument (Roche Life Science) in $1000 \mu \mathrm{L}$ of DMEM medium supplemented with $2 \%$ heat-inactivated FBS. Tissue homogenates were clarified by centrifugation at 10,000 rpm for 5 min and stored at $-80^{\circ} \mathrm{C}$. RNA was extracted using the MagMax mirVana Total RNA isolation kit (Thermo Fisher Scientific) on the Kingfisher Flex extraction robot (Thermo Fisher Scientific). RNA was reverse transcribed and amplified using the TaqMan RNA-to-CT 1-Step Kit (Thermo Fisher Scientific). Reverse transcription was carried out at $48^{\circ} \mathrm{C}$ for $15 \mathrm{~min}$ followed by $2 \mathrm{~min}$ at $95^{\circ} \mathrm{C}$. Amplification was accomplished over 50 cycles as follows: $95^{\circ} \mathrm{C}$ for $15 \mathrm{~s}$ and $60^{\circ} \mathrm{C}$ for $1 \mathrm{~min}$. Copies of SARS-CoV-2 N gene RNA in samples were determined using a previously published assay ${ }^{53}$. Briefly, a TaqMan assay was designed to target a highly conserved region of the $\mathrm{N}$ gene (Forward primer: ATGCTGCAATCGTGCTACAA; Reverse primer: GACTGCCGCCTCTGCTC; Probe: /56-

FAM/TCAAGGAAC/ZEN/AACATTGCCAA/3IABkFQ/). This region was included in an RNA standard to allow for copy number determination down to 10 copies per reaction. The reaction mixture contained final concentrations of primers and probe of 500 and $100 \mathrm{nM}$, respectively.

Plaque assay. Vero-TMPRSS2-hACE2 cells were seeded at a density of $1 \times 10^{5}$ cells per well in 24 -well tissue culture plates. The following day, medium was removed and replaced with $200 \mu \mathrm{L}$ of material to be titrated diluted serially in DMEM supplemented with $2 \%$ FBS. One hour later, 1 mL of methylcellulose overlay was added. Plates were incubated for $72 \mathrm{~h}$, then fixed with $4 \%$ paraformaldehyde (final concentration) in PBS for 20 min. Plates were stained with $0.05 \%(w / v)$ crystal violet in $20 \%$ methanol and washed twice with distilled, deionized water.

Cytokine and chemokine protein measurements. Lung homogenates were incubated with Triton-X-100 ( $1 \%$ final concentration) for $1 \mathrm{~h}$ at room temperature to inactivate SARS-CoV-2. Homogenates then were analyzed for cytokines and chemokines by Eve Technologies Corporation (Calgary, AB, Canada) using their Mouse Cytokine Array / Chemokine Array 31-Plex (MD31) platform.

Data availability. All data supporting the findings of this study are available within the paper and are available from the corresponding author upon request.

Statistical analysis. All statistical tests were performed as described in the indicated figure legends using Prism 8.0. Statistical significance was determined using an ordinary one-way ANOVA with Dunnett's post-test when comparing three or more groups. The number of independent experiments used are indicated in the relevant Figure legends.

\section{Declarations}

\section{ACKNOWLEDGEMENTS}

This study was supported by grants and contracts from NIH (R01 Al157155, U01 Al151810, U01Al141990, U01Al 151810, R01 Al118938, 75N93019C00051, HHSN272201400006C, HHSN272201400008C, HHSN75N93019C00074, and HHSN272201400006C), the Children's Discovery Institute (PDII2018702) and the Defense Advanced Research Project Agency (HR0011-18-2-0001), the Dolly Parton COVID-19 Research Fund at Vanderbilt University, , a grant from Fast Grants, Mercatus Center, George Mason University, and the Future Insight Prize (Merck KGaA; to J.E.C). J.B.C. is supported by a Helen Hay Whitney Foundation postdoctoral fellowship, E.S.W. is supported by F30 Al152327, and S.J.Z. is supported by NIH grant T32 Al095202. P-Y.S. is supported by awards from the Sealy \& Smith Foundation, the Kleberg Foundation, the John S. Dunn Foundation, the Amon G. Carter Foundation, the Gilson Longenbaugh Foundation, and the Summerfield Robert Foundation. We thank Rachel Nargi and Robert Carnahan for assistance with mAb generation and purification and Stephen Tahan for some of the deep sequencing analysis. The content is solely the responsibility of the authors and does not represent the official views of the U.S. government or other sponsors.

\section{AUTHOR CONTRIBUTIONS}

R.E.C. performed and analyzed neutralization assays. R.E.C., E.S.W., and J.B.C. performed mouse experiments. R.E.C., E.S.W., J.B.C., B.Y., and S.S. performed viral burden analyses. X.X. designed and generated the recombinant SARS-CoV-2 variant viruses. R.E.C. and L.A.V. propagated and validated SARS-CoV-2 viruses. L.D., S.A.H., and D.W. performed the deep sequencing analysis. I.D.A. and S.S. performed Sanger sequencing analyses. T.L.D., T.L.B., and A.C.M.B. performed the hamster studies. T.L.D. and A.J performed viral burden and inflammatory gene analysis. J.M.E. and D.H.F. performed structural analysis. Z.L. generated escape mutants. E.S.W. quantified serum antibody concentrations. J.B.C. and T.L.B. performed plaque assays. D.C., P.G., S.J.Z., W.B.S., J.E.C., A.H.E., 
W.B.S., and L.P. provided mAbs. M.G.K., R.A., and C.Y.C. provided SARS-CoV-2 strains. P.Y.S., A.H.E., D.C., A.C.M.B. and M.S.D. obtained funding and supervised the research. R.E.C, E.S.W., J.B.C., and M.S.D. wrote the initial draft, with the other authors providing editorial comments.

\section{COMPETING FINANCIAL INTERESTS}

M.S.D. is a consultant for Inbios, Vir Biotechnology, Fortressa Biotech, and Carnival Corporation, and on the Scientific Advisory Boards of Moderna and Immunome. The Diamond laboratory has received funding support in sponsored research agreements from Moderna, Vir Biotechnology, Kaleido, and Emergent BioSolutions. J.E.C. has served as a consultant for Eli Lilly and Luna Biologics, is a member of the Scientific Advisory Boards of CompuVax and Meissa Vaccines and is Founder of IDBiologics. The Crowe laboratory at Vanderbilt University Medical Center has received sponsored research agreements from Takeda, AstraZeneca and IDBiologics. Vanderbilt University (J.E.C.) and Washington University (A.H.E., A.C.M.B., M.S.D.) have applied for patents related to antibodies described in this paper. The Ellebedy laboratory has received funding support in sponsored research agreements from AbbVie Inc. and Emergent

BioSolutions. The Boon laboratory has received funding support in sponsored research agreements from Al Therapeutics, GreenLight Biosciences, AbbVie, and Nano targeting \& Therapy Biopharma. The Shi laboratory has received sponsored research agreements from Pfizer, Gilead, Merck, and IGM Sciences Inc. D.C. and L.P. are employees of Vir Biotechnology and may hold equity in Vir Biotechnology. L.P. is a former employee and may hold equity in Regeneron Pharmaceuticals. W.B.S. is an employee of AbbVie and may hold equity.

\section{References}

1. Chen, R.E., et al. Resistance of SARS-CoV-2 variants to neutralization by monoclonal and serum-derived polyclonal antibodies. Nat Med (2021).

2. Wang, P., et al. Antibody Resistance of SARS-CoV-2 Variants B.1.351 and B.1.1.7. Nature (2021).

3. Wang, Z., et al. mRNA vaccine-elicited antibodies to SARS-CoV-2 and circulating variants. Nature (2021).

4. Sempowski, G.D., Saunders, K.O., Acharya, P., Wiehe, K.J. \& Haynes, B.F. Pandemic Preparedness: Developing Vaccines and Therapeutic Antibodies For COVID-19. Cell 181, 1458-1463 (2020).

5. Letko, M., Marzi, A. \& Munster, V. Functional assessment of cell entry and receptor usage for SARS-CoV-2 and other lineage B betacoronaviruses. Nature microbiology 5, 562-569 (2020).

6. Pinto, D., et al. Cross-neutralization of SARS-CoV-2 by a human monoclonal SARS-CoV antibody. Nature 583, 290-295 (2020).

7. Cao, Y., et al. Potent neutralizing antibodies against SARS-CoV-2 identified by high-throughput single-cell sequencing of convalescent patients' B cells. Cell 182, 73-84 (2020).

8. Zost, S.J., et al. Rapid isolation and profiling of a diverse panel of human monoclonal antibodies targeting the SARS-CoV-2 spike protein. Nat Med 26, 1422-1427 (2020).

9. Barnes, C.O., et al. SARS-CoV-2 neutralizing antibody structures inform therapeutic strategies. Nature 588, 682-687 (2020).

10. Tortorici, M.A., et al. Ultrapotent human antibodies protect against SARS-CoV-2 challenge via multiple mechanisms. Science 370, 950-957 (2020).

11. Rathe, J.A., et al. SARS-CoV-2 Serologic Assays in Control and Unknown Populations Demonstrate the Necessity of Virus Neutralization Testing. $J$ Infect $\operatorname{Dis}(2020)$.

12. Wibmer, C.K., et al. SARS-CoV-2 501Y.V2 escapes neutralization by South African COVID-19 donor plasma. bioRxiv (2021).

13. Tada, T., et al. Neutralization of viruses with European, South African, and United States SARS-CoV-2 variant spike proteins by convalescent sera and BNT162b2 mRNA vaccine-elicited antibodies. bioRxiv (2021).

14. Leung, K., Shum, M.H., Leung, G.M., Lam, T.T. \& Wu, J.T. Early transmissibility assessment of the N501Y mutant strains of SARS-CoV-2 in the United Kingdom, October to November 2020. Euro Surveill 26(2021).

15. Xie, X., et al. Neutralization of SARS-CoV-2 spike 69/70 deletion, E484K and N501Y variants by BNT162b2 vaccine-elicited sera. Nat Med (2021).

16. Klimstra, W.B., et al. SARS-CoV-2 growth, furin-cleavage-site adaptation and neutralization using serum from acutely infected hospitalized COVID-19 patients. J Gen Virol 101, 1156-1169 (2020).

17. Johnson, B.A., et al. Loss of furin cleavage site attenuates SARS-CoV-2 pathogenesis. Nature (2021).

18. Winkler, E.S., et al. SARS-CoV-2 infection of human ACE2-transgenic mice causes severe lung inflammation and impaired function. Nat Immuno/ 21, 13271335 (2020).

19. McCray, P.B., Jr., et al. Lethal infection of K18-hACE2 mice infected with severe acute respiratory syndrome coronavirus. J Viro/ 81, 813-821 (2007).

20. Winkler, E.S., et al. Human neutralizing antibodies against SARS-CoV-2 require intact Fc effector functions for optimal therapeutic protection. Cel/ 184, 1804-1820.e1816 (2021).

21. Rathnasinghe, R., et al. The N501Y mutation in SARS-CoV-2 spike leads to morbidity in obese and aged mice and is neutralized by convalescent and postvaccination human sera. medRxiv : the preprint server for health sciences (2021).

22. Gu, H., et al. Adaptation of SARS-CoV-2 in BALB/c mice for testing vaccine efficacy. Science 369, 1603-1607 (2020).

23. Oliphant, T., et al. Development of a humanized monoclonal antibody with therapeutic potential against West Nile virus. Nature Medicine $11,522-530$ (2005).

24. Giamarellos-Bourboulis, E.J., et al. Complex Immune Dysregulation in COVID-19 Patients with Severe Respiratory Failure. Cell Host Microbe (2020).

25. Rosenfeld, R., et al. Post-exposure protection of SARS-CoV-2 lethal infected K18-hACE2 transgenic mice by neutralizing human monoclonal antibody. Nat Commun 12, 944 (2021). 
26. García-Arriaza, J., et al. COVID-19 vaccine candidates based on modified vaccinia virus Ankara expressing the SARS-CoV-2 spike induce robust T- and Bcell immune responses and full efficacy in mice. $J$ Virol (2021).

27. Zheng, J., et al. COVID-19 treatments and pathogenesis including anosmia in K18-hACE2 mice. Nature 589, 603-607 (2021).

28. Hassan, A.O., et al. A Single-Dose Intranasal ChAd Vaccine Protects Upper and Lower Respiratory Tracts against SARS-CoV-2. Cell 183, 169-184.e113 (2020).

29. Zhou, D., et al. Robust SARS-CoV-2 infection in nasal turbinates after treatment with systemic neutralizing antibodies. Cell Host Microbe (2021).

30. Andreano, E., et al. Extremely potent human monoclonal antibodies from COVID-19 convalescent patients. Cell 184, 1821-1835.e1816 (2021).

31. Cobey, S., Larremore, D.B., Grad, Y.H. \& Lipsitch, M. Concerns about SARS-CoV-2 evolution should not hold back efforts to expand vaccination. Nat Rev Immunol, 1-6 (2021).

32. Shen, X., et al. Neutralization of SARS-CoV-2 Variants B.1.429 and B.1.351. N Engl J Med (2021).

33. McCallum, M., et al. SARS-CoV-2 immune evasion by variant B.1.427/B.1.429. bioRxiv (2021).

34. Lundgren, J.D., et al. A Neutralizing Monoclonal Antibody for Hospitalized Patients with Covid-19. N Engl J Med 384, 905-914 (2021).

35. Gottlieb, R.L., et al. Effect of Bamlanivimab as Monotherapy or in Combination With Etesevimab on Viral Load in Patients With Mild to Moderate COVID19: A Randomized Clinical Trial. Jama 325, 632-644 (2021).

36. Starr, T.N., Greaney, A.J., Dingens, A.S. \& Bloom, J.D. Complete map of SARS-CoV-2 RBD mutations that escape the monoclonal antibody LY-CoV555 and its cocktail with LY-CoV016. Cell reports. Medicine, 100255 (2021).

37. Schmitz, A.J., et al. A public vaccine-induced human antibody protects against SARS-CoV-2 and emerging variants. bioRxiv (2021).

38. Tian, F., et al. Mutation N501Y in RBD of Spike Protein Strengthens the Interaction between COVID-19 and its Receptor ACE2. BioRxiv (2021).

39. Bailey, A.L. \& Diamond, M.S. A Crisp(r) New Perspective on SARS-CoV-2 Biology. Cell 184, 15-17 (2021).

40. Pierson, T.C. \& Diamond, M.S. A game of numbers: the stoichiometry of antibody-mediated neutralization of flavivirus infection. Progress in molecular biology and translational science 129, 141-166 (2015).

41. Graham, C., et al. Neutralization potency of monoclonal antibodies recognizing dominant and subdominant epitopes on SARS-CoV-2 Spike is impacted by the B.1.1.7 variant. Immunity (2021).

42. Rees-Spear, C., et al. The effect of spike mutations on SARS-CoV-2 neutralization. Cell Rep 34, 108890 (2021).

43. Zhou, D., et al. Evidence of escape of SARS-CoV-2 variant B.1.351 from natural and vaccine-induced sera. Cell (2021).

44. Baum, A., et al. Antibody cocktail to SARS-CoV-2 spike protein prevents rapid mutational escape seen with individual antibodies. Science (2020).

45. Goddard, T.D., et al. UCSF ChimeraX: Meeting modern challenges in visualization and analysis. Protein Sci 27, 14-25 (2018).

46. Zang, R., et al. TMPRSS2 and TMPRSS4 promote SARS-CoV-2 infection of human small intestinal enterocytes. Sci Immuno/5(2020).

47. Plante, J.A., et al. Spike mutation D614G alters SARS-CoV-2 fitness. Nature (2020).

48. Alsoussi, W.B., et al. A Potently Neutralizing Antibody Protects Mice against SARS-CoV-2 Infection. $J$ Immunol (2020).

49. Baum, A., et al. REGN-COV2 antibodies prevent and treat SARS-CoV-2 infection in rhesus macaques and hamsters. Science (2020).

50. Jones, B.E., et al. LY-CoV555, a rapidly isolated potent neutralizing antibody, provides protection in a non-human primate model of SARS-CoV-2 infection. bioRxiv (2020).

51. Shi, R., et al. A human neutralizing antibody targets the receptor-binding site of SARS-CoV-2. Nature 584, 120-124 (2020).

52. Liu, Z., et al. Identification of SARS-CoV-2 spike mutations that attenuate monoclonal and serum antibody neutralization. Cell Host Microbe 29, 477488.e474 (2021).

53. Case, J.B., Bailey, A.L., Kim, A.S., Chen, R.E. \& Diamond, M.S. Growth, detection, quantification, and inactivation of SARS-CoV-2. Virology 548, 39-48 (2020).

54. Zost, S.J., et al. Potently neutralizing and protective human antibodies against SARS-CoV-2. Nature 584, $443-449$ (2020).

55. Dong, J., et al. Genetic and structural basis for recognition of SARS-CoV-2 spike protein by a two-antibody cocktail. bioRxiv (2021).

56. Hansen, J., et al. Studies in humanized mice and convalescent humans yield a SARS-CoV-2 antibody cocktail. Science 369, 1010-1014 (2020).

57. Starr, T.N., et al. Prospective mapping of viral mutations that escape antibodies used to treat COVID-19. bioRxiv (2020).

58. Wang, C., et al. A human monoclonal antibody blocking SARS-CoV-2 infection. Nat Commun 11, 2251 (2020).

59. Starr, T.N., et al. Antibodies to the SARS-CoV-2 receptor-binding domain that maximize breadth and resistance to viral escape. bioRxiv (2021).

60. Jones, B.E., et al. The neutralizing antibody, LY-CoV555, protects against SARS-CoV-2 infection in non-human primates. Sci Transl Med (2021).

\section{Tables}

Table 1. Neutralizing monoclonal antibodies 


\begin{tabular}{|c|c|c|c|c|c|}
\hline & Antibody & Class & $\begin{array}{l}\text { Structural } \\
\text { binding } \\
\text { site } \\
\text { (amino } \\
\text { acid } \\
\text { position } \\
\text { in spike } \\
\text { protein) }\end{array}$ & $\begin{array}{l}\text { Functional } \\
\text { Residues }\end{array}$ & References \\
\hline \multirow[t]{3}{*}{$\begin{array}{c}\text { Vanderbilt } \\
\text { niversity/AstraZeneca* }\end{array}$} & COV2-2130 & RBM & $\begin{array}{l}345-346, \\
439-441 \\
443-447 \\
449-450 \\
452,484, \\
490,492- \\
494\end{array}$ & $\begin{array}{l}\text { Mutational } \\
\text { analysis/yeast } \\
\text { display: R346, } \\
\text { K444, G447, } \\
\text { N448 } \\
\text { VSV-SARS- } \\
\text { CoV-2 escape: } \\
\text { K444R/E } \\
\text { Authentic } \\
\text { SARS-CoV-2 } \\
\text { escape: } \\
\text { N74K, R346I }\end{array}$ & $8,54,55$ \\
\hline & COV2-2196 & RBM & $\begin{array}{l}455-456, \\
475-479 \\
484-489 \\
493\end{array}$ & $\begin{array}{l}\text { Mutational } \\
\text { analysis/yeast } \\
\text { display: } \\
\text { G476, F486, } \\
\text { N487, Y489 } \\
\text { VSV-SARS- } \\
\text { CoV-2 escape: } \\
\text { None } \\
\text { identified } \\
\text { Authentic } \\
\text { SARS-CoV-2 } \\
\text { escape: None } \\
\text { identified }\end{array}$ & $8,54,55$ \\
\hline & COV2-2130/COV2-2196 & & & $\begin{array}{l}\text { Mutational } \\
\text { analysis/yeast } \\
\text { display: Not } \\
\text { determined } \\
\text { VSV-SARS- } \\
\text { CoV-2: None } \\
\text { identified } \\
\\
\text { Authentic } \\
\text { SARS-CoV-2: } \\
\text { None } \\
\text { identified }\end{array}$ & 55 \\
\hline \multirow[t]{2}{*}{ Regeneron* } & REGN10933 & RBM & $\begin{array}{l}403,406, \\
417,421, \\
449,453, \\
455-456, \\
473-478, \\
484-490 \\
492-496, \\
498,501\end{array}$ & $\begin{array}{l}\text { Mutational } \\
\text { analysis/yeast } \\
\text { display: K417, } \\
\text { Y453, L455, } \\
\text { E484, G485, } \\
\text { F486, N487, } \\
\text { Y489, Q493 } \\
\text { VSV-SARS- } \\
\text { CoV-2 escape: } \\
\text { K417E, } \\
\text { Y453F, } \\
\text { L455F, } \\
\text { F486V, } \\
\text { Q493K } \\
\text { Authentic } \\
\text { SARS-CoV-2 } \\
\text { escape: } \\
\text { F486I, } \\
\text { Y489H, } \\
\text { Q493K } \\
\text { (identified in } \\
\text { patients } \\
\text { treated with } \\
\text { REGN-COV2) } \\
\end{array}$ & 56,57 \\
\hline & REGN10987 & RBM & $\begin{array}{l}346,439- \\
441,443- \\
450,498- \\
501\end{array}$ & $\begin{array}{l}\text { Mutational } \\
\text { analysis/yeast } \\
\text { display: } \\
\text { N439, N440, } \\
\text { K444, V445, } \\
\text { G446, G447, } \\
\text { N448, N439, } \\
\text { N440, P499 } \\
\text { VSV-SARS- } \\
\text { CoV-2 escape: }\end{array}$ & 56,57 \\
\hline
\end{tabular}




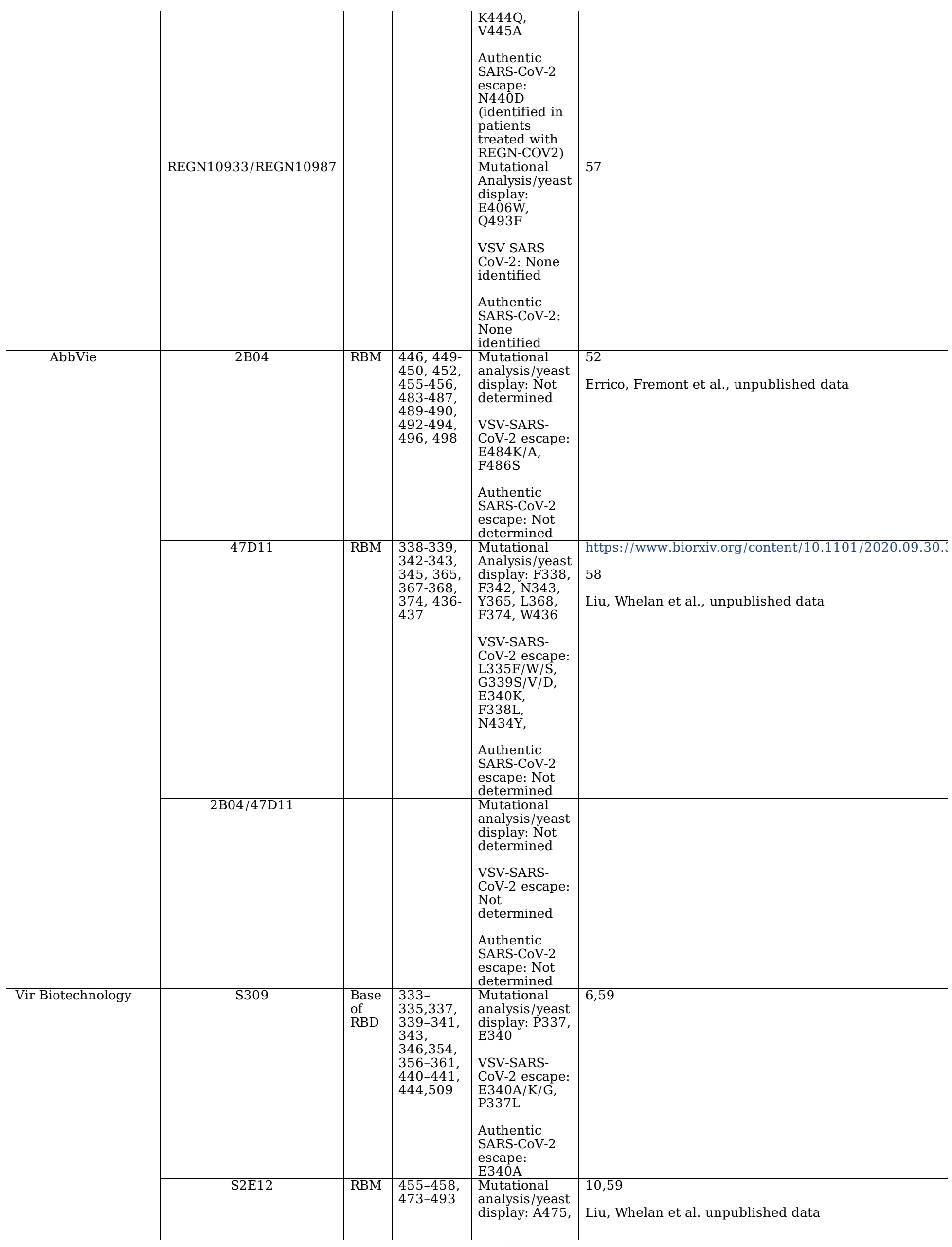

Page 11/17 


\begin{tabular}{|c|c|c|c|c|c|}
\hline & & & & \begin{tabular}{|l} 
G476, F486, \\
N487, Y489 \\
VSV-SARS- \\
CoV-2 escape: \\
A475D, \\
G476D/S, \\
G485D \\
\\
Authentic \\
SARS-CoV-2 \\
escape: Not \\
determined
\end{tabular} & \\
\hline & S309/S2E12 & & & \begin{tabular}{|l|} 
Mutational \\
analysis/yeast \\
display: Not \\
determined \\
VSV-SARS- \\
CoV-2 escape: \\
Not \\
determined \\
Authentic \\
SARS-CoV-2 \\
escape: Not \\
determined
\end{tabular} & \\
\hline Lilly* & LY-CoV555 & RBM & $\begin{array}{l}34-444, \\
455-456, \\
484,486- \\
490,493- \\
494\end{array}$ & \begin{tabular}{|l|} 
Yeast display: \\
L452, I472, \\
V483, E848, \\
G485, F486, \\
F490, Q493, \\
S494 \\
VSV-SARS- \\
CoV-2 escape: \\
Not \\
determined \\
Authentic \\
SARS-CoV-2 \\
escape: \\
E484K
\end{tabular} & $2,36,60$ \\
\hline
\end{tabular}

*Corresponding antibody sequence

\section{Figures}


a

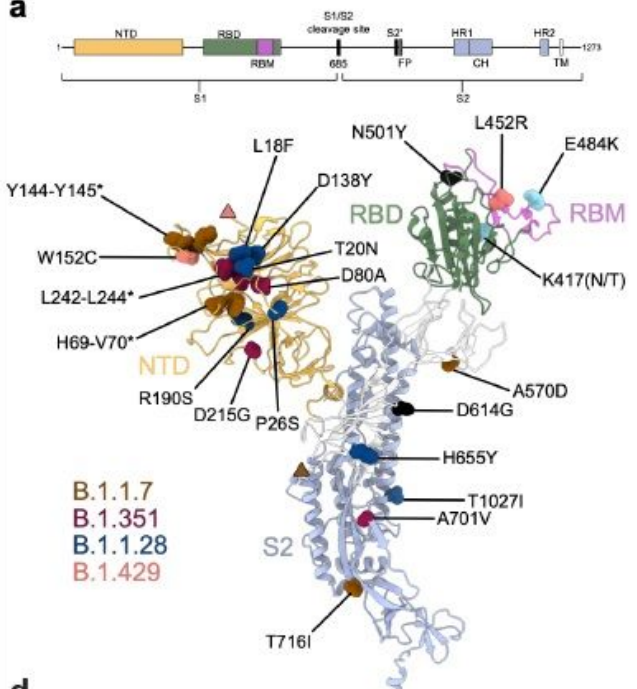

b

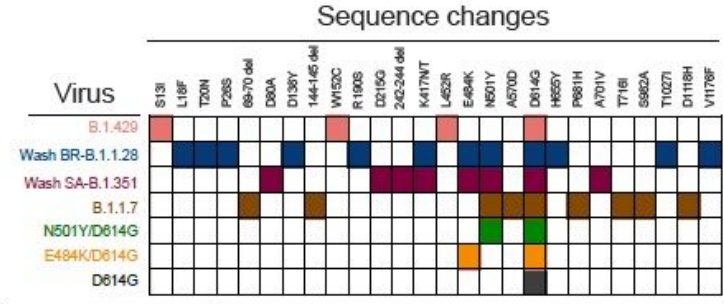

c

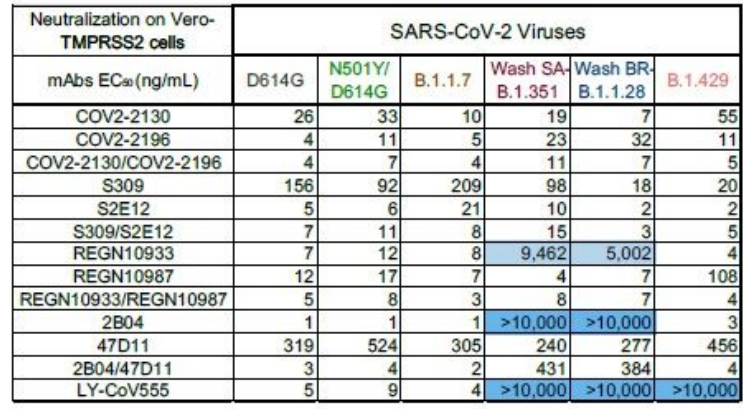

d
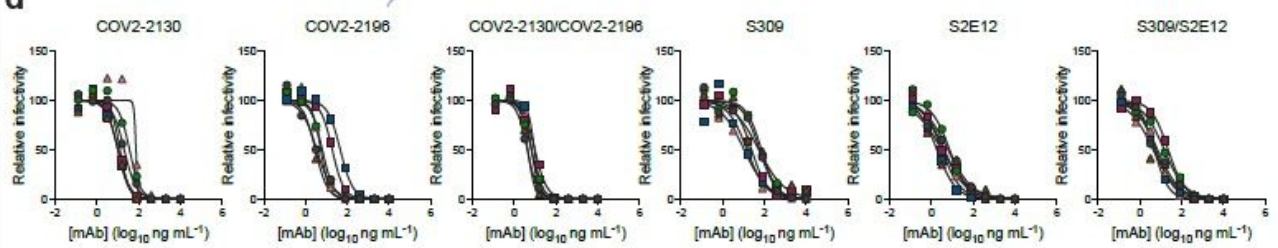

REGN10933
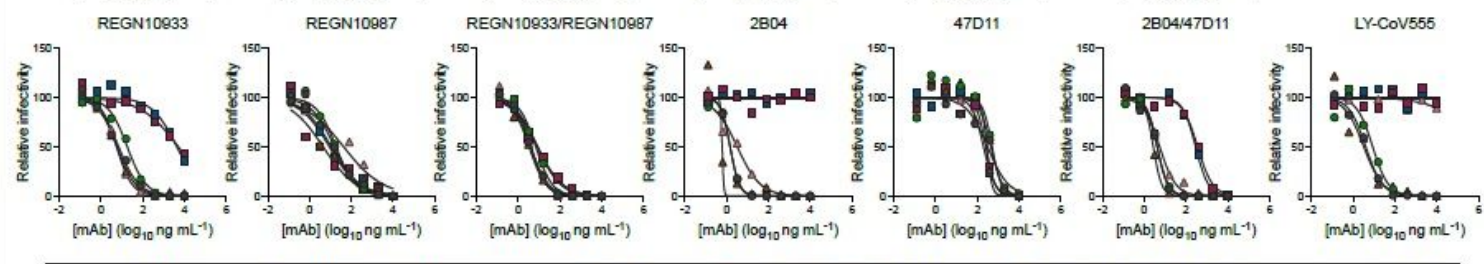

\section{Figure 1}

Neutralization of SARS-CoV-2 variant strains by clinically relevant mAbs. (a) SARS-CoV-2 variant substitutions mapped onto the structure of the spike protein. Schematic layout of the spike protein monomer is depicted at the top. Structure of spike monomer (PDB: 7C2L with RBD from PDB: 6W41) is depicted as a cartoon, with NTD, RBD, RBM, and S2 colored orange, green, magenta, and light blue, respectively. Substitutions for each variant (B.1.1.7: 69-70 deletion, 144145 deletion, N501Y, A570D, D614G, P681H, and T716l; B.1.351: 242-244 deletion, D80A, D215G, K417N, E484K, N501Y, D614G, and A701V; B.1.1.28: L18F, T20N, P26S, D138Y, R190S, K417T, E484K, N501Y, D614G, H655Y, T1027l; B.1.429: S13I, W152C, L452R) are shown as spheres and colored accordingly. Substitutions shown in cyan (E484K and K417[N/T]) are shared by B.1.351 and B.1.1.28. Substitutions shown in black (D614G and N501Y) are shared by B.1.1.7, B.1.351, and B.1.1.28. Pink and brown triangles show approximate locations of $\mathrm{S} 13$ and P681, which were not modelled in the original structures. Structural figure generated using UCSF ChimeraX45. (b) Viruses used with indicated mutations in the spike protein. (c) Summary of EC50 values (ng/mL) of neutralization of SARS-CoV-2 viruses performed in Vero-TMPRSS2 cells. Blue shading of cells indicates a partial (EC50 >1,000 ng/mL) or complete (EC50> $10,000 \mathrm{ng} / \mathrm{mL}$ ) loss of neutralizing activity. (d) Neutralization curves comparing the sensitivity of SARS-CoV-2 strains to the indicated individual or combinations of mAbs. Data are representative of two to five experiments, each performed in technical duplicate. 


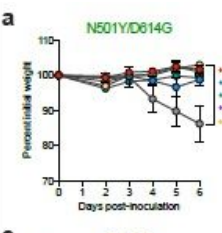

b
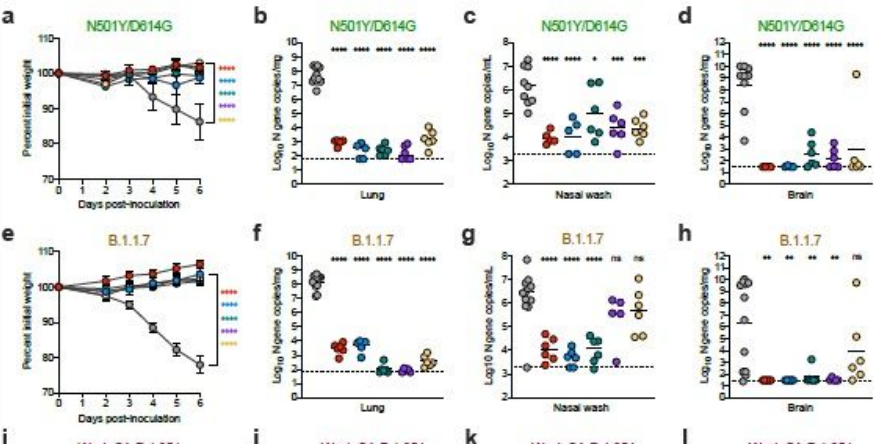

f

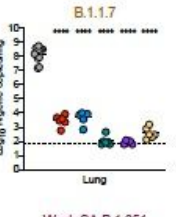

g
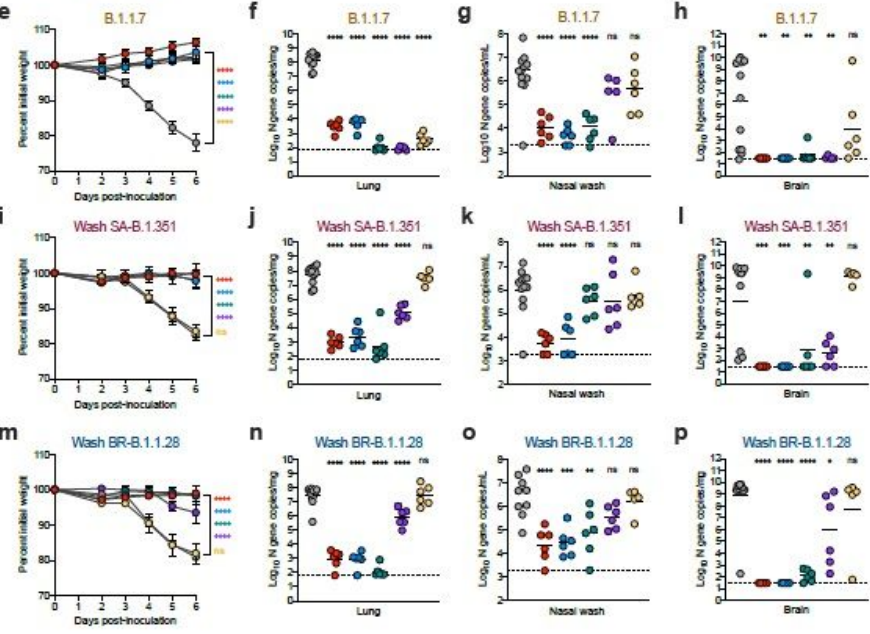

K18-hACE2 Transgenic Mice

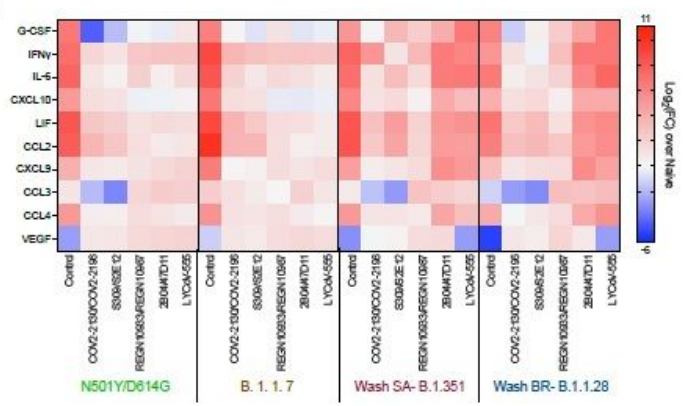

Figure 2

Antibody prophylaxis against SARS-CoV-2 variants in K18-hACE2 mice. (a-q) 8-10-week-old female and male K18-hACE2 transgenic mice received 40 $\square g$ ( 2 $\mathrm{mg} / \mathrm{kg}$ ) of the indicated mAb treatment by intraperitoneal injection one day before intranasal inoculation with 103 FFU of the indicated SARS-CoV-2 strain. Tissues were collected at 6 dpi. ( $a, e, i, m)$ Weight change following infection with SARS-CoV-2 (mean \pm SEM; $n=6-12$ mice per group, two experiments; oneway ANOVA with Dunnett's test of area under the curve: ns, not significant, $\star \star \star \star ~ P<0.0001)$. Viral RNA levels in the lung (b, $f, j, n)$, nasal washes (c, $g, k, 0)$, and brain ( $d, h, l, p)$ were measured ( $n=6-12$ mice per group, two experiments; one-way ANOVA with Dunnett's test with comparison to control mAb: ns, not significant, ${ }^{*} P<0.05$, ** $P<0.01$, ${ }^{\star * \star} P<0.001$, $\left.{ }^{\star \star * \star} P<0.0001\right)$. Dotted line indicates the limit of detection of the assay. Heat map of cytokine and chemokine protein expression levels in lung homogenates collected at $6 \mathrm{dpi}$ from the indicated groups (q). Data are presented as log2 fold-change over naïve animals. Blue, reduction; red, increase. 
a

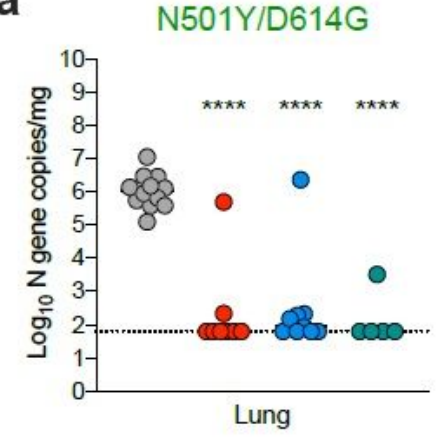

e

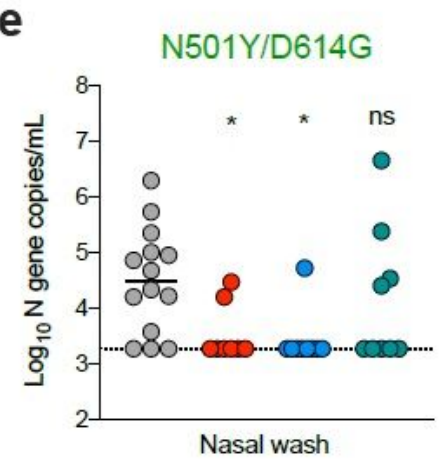

Control $\mathrm{mAb}$ b

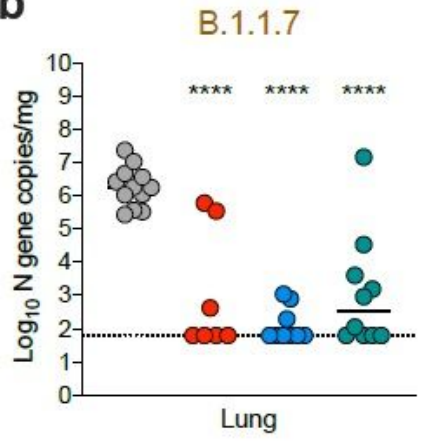

f

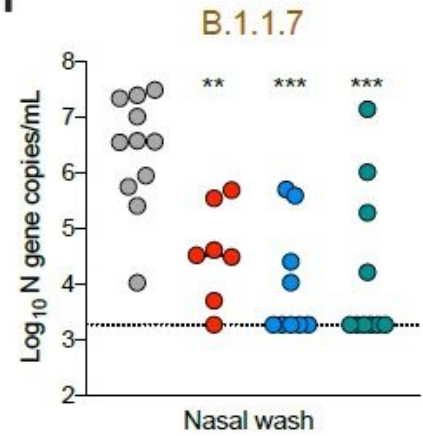

- COV2-2130/COV2-2196
C

Wash SA-B.1.351

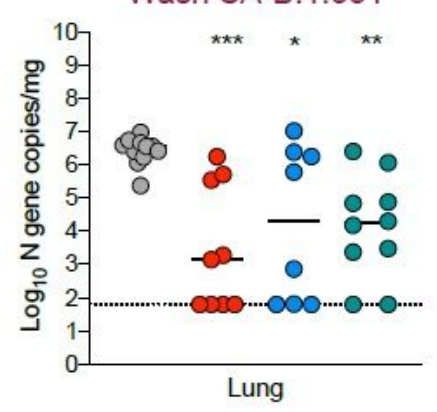

g

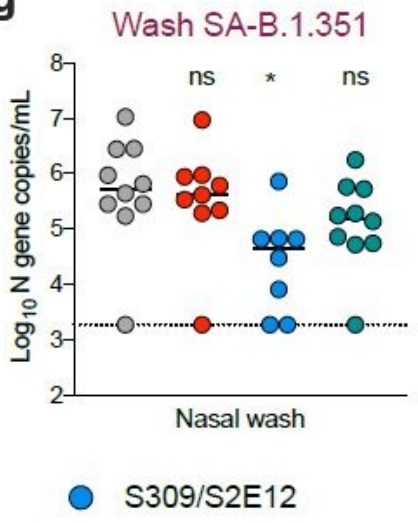

d

Wash BR-B.1.1.28

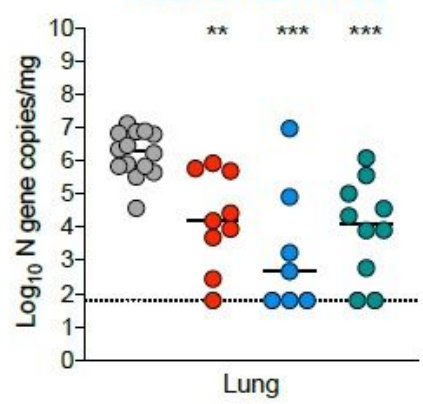

h

Wash BR-B.1.1.28

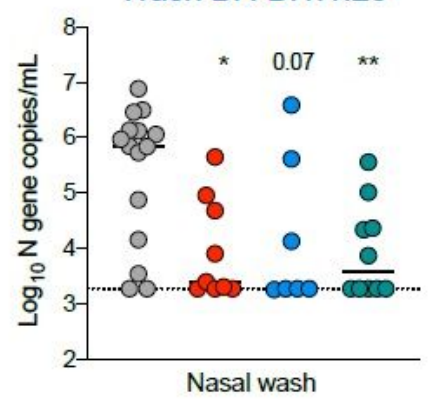

REGN10933/REGN10987

\section{S2 Mice}

Figure 3

Antibody-mediated protection against SARS-CoV-2 variants in 129S2 mice. 6-7-week-old female and male immunocompetent $129 \mathrm{~S} 2$ mice received 40 mg ( 2 $\mathrm{mg} / \mathrm{kg}$ ) of the indicated mAb treatment by intraperitoneal injection one day before intranasal inoculation with 103 FFU of WA1/2020 N501Y/D614G, Wash SAB.1.351, or Wash BR-B.1.1.28 and $105 \mathrm{FFU}$ of B.1.1.7. Tissues were collected at 3 dpi. Viral RNA levels in the lung (a-d) or nasal washes (e-h) were determined ( $n$ = 7-12 mice per group, pooled from two experiments; one-way ANOVA with Dunnett's test with comparison to control mAb: ns, not significant, * $P<0.05$, ** $P$ $\left.<0.01,{ }^{* *} P<0.001\right)$. Dotted line indicates the limit of detection of the assay. 

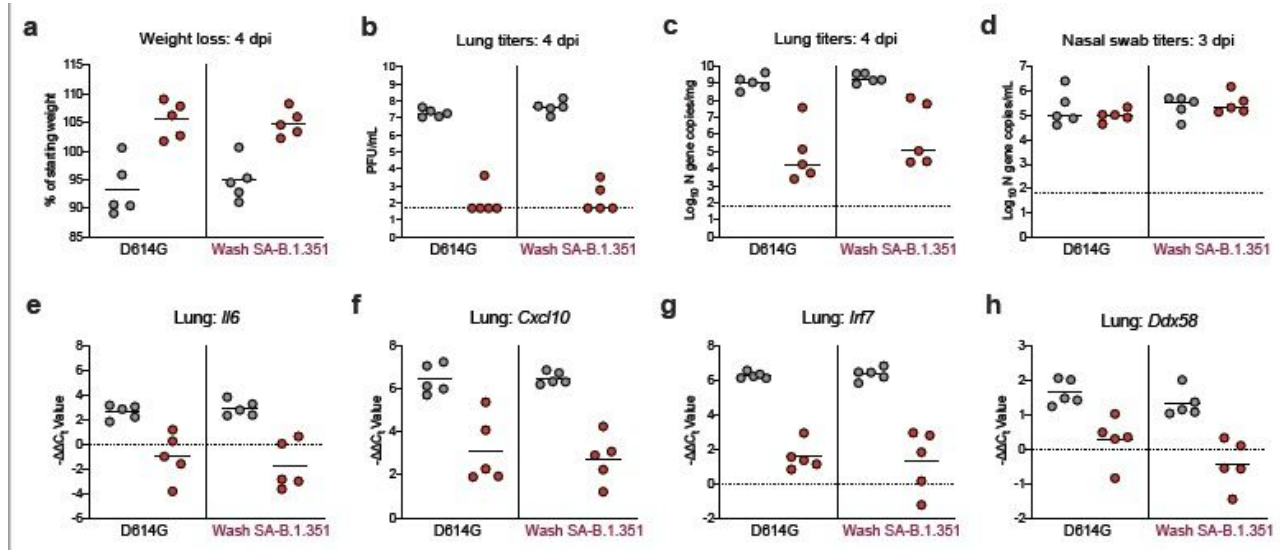

- Control mAb

- COV2-2130/COV2-2196 (10 mg/kg)

Syrian Golden Hamster
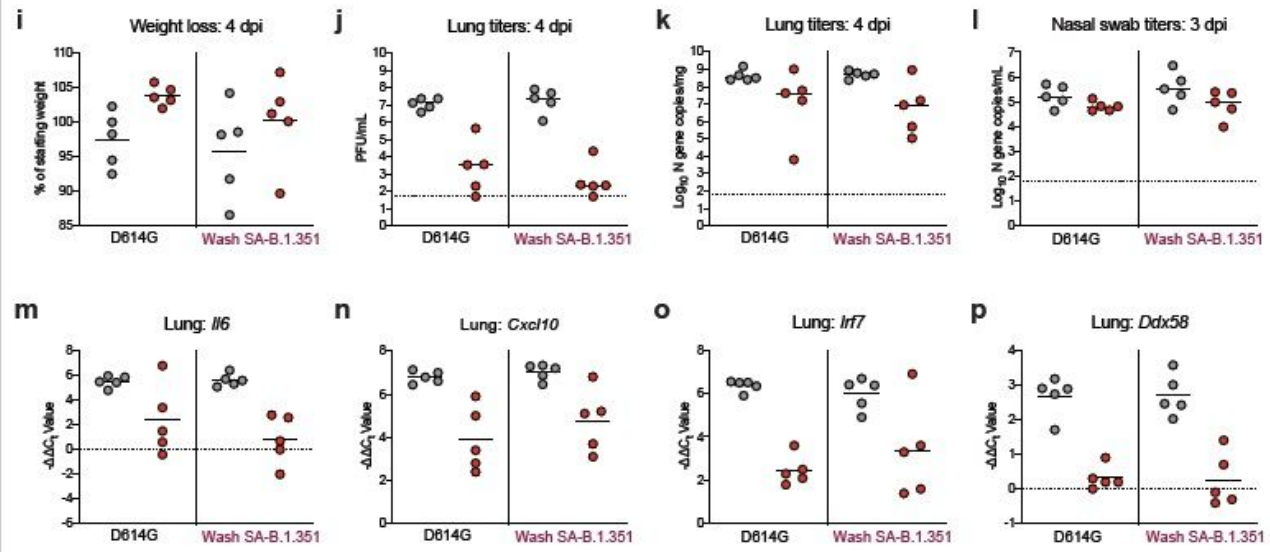

- Control $\mathrm{mAb}$

COV2-2130/COV2-2196 (4 mg/kg)

Syrian Golden Hamster

Figure 4

COV2-2130/COV2-2196 antibody cocktail protects hamsters against historical and variant SARS-CoV-2 strains. Six-week-old male Syrian golden hamsters received a single $800 \mathrm{mg}(\sim 10 \mathrm{mg} / \mathrm{kg})(\mathrm{a}-\mathrm{h})$ or $320 \mathrm{mg}(\sim 4 \mathrm{mg} / \mathrm{kg})$ dose (i-p) of COV2-2130/COV2196 mAb cocktail or control mAb by intraperitoneal injection one day before intranasal inoculation with 5 x 105 FFU of WA1/2020 D614G or Wash SA-B.1.351 viruses. Nasal swabs and lung tissues were collected at 3 and 4 dpi, respectively. (a, i) Weight change following infection with SARS-CoV-2 (mean \pm SEM; $n=5$ animals per group, one experiment). Infectious virus in the lung $(b, j)$ or viral RNA levels in the lung $(c, k)$ and nasal swabs $(d, l)$ were determined $(n=5$ animals per group, one experiment). Dotted line indicates the limit of detection of the assay. (e-h, m-p) Cytokine and inflammatory gene expression in lung homogenates collected at $6 \mathrm{dpi}$ from indicated groups. Values were calculated using the DDCt method compared to a naïve control group. Because data were obtained from a single experiment (even with multiple animals), statistical analysis was not performed. 
a

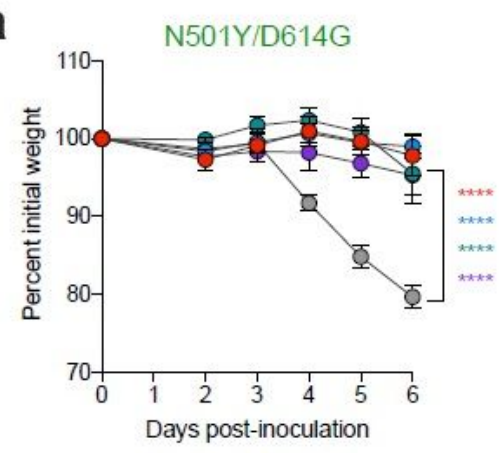

e

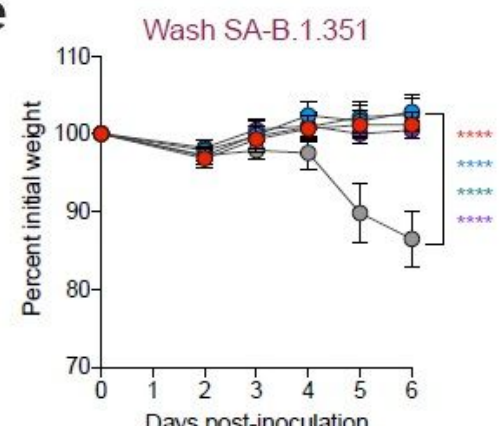

Control mAb b

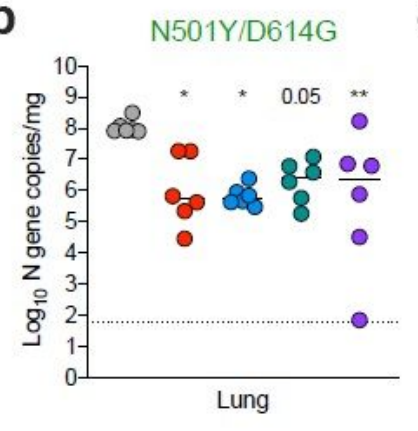

f

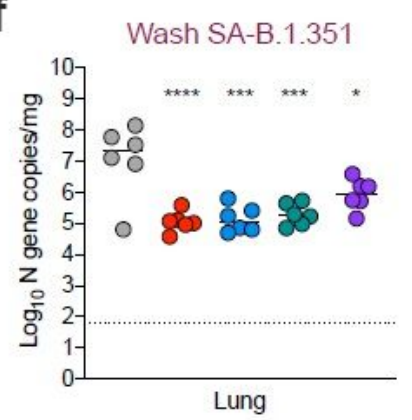

C

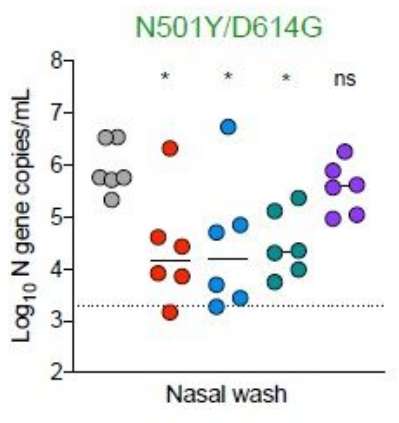

g

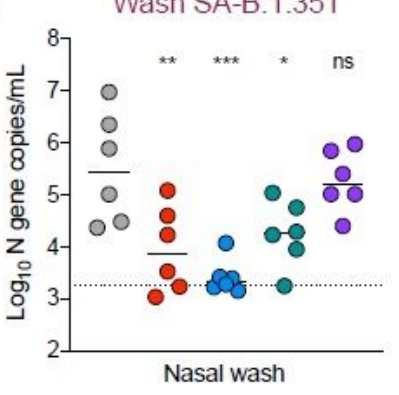

d

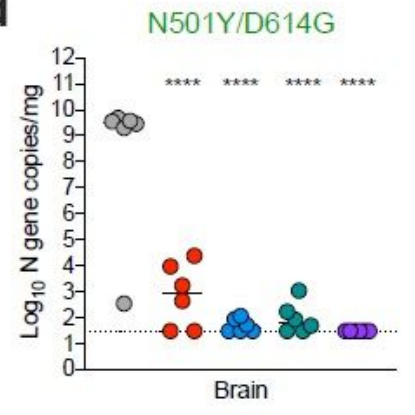

h

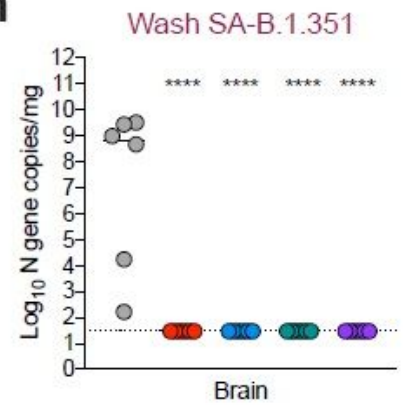

S309/S2E12

REGN10933/REGN10987

2B04/47D11

\section{K18-hACE2 Transgenic Mice}

\section{Figure 5}

Post-exposure antibody therapy against SARS-CoV-2 variants in K18-hACE2 mice. (a-h) 8-10-week-old female and male K18-hACE2 transgenic mice were administered $103 \mathrm{FFU}$ of the indicated SARS-CoV-2 strain by intranasal inoculation. One day later, mice received $200 \mathrm{mg}(\sim 10 \mathrm{mg} / \mathrm{kg})$ of the indicated mAb treatment by intraperitoneal injection. Tissues were collected at $6 \mathrm{dpi}$. (a, e) Weight change following infection with SARS-CoV-2 (mean \pm SEM; $\mathrm{n}=6$ mice per group, two experiments; one-way ANOVA with Dunnett's test of area under the curve: $\star \star \star \star ~ P<0.0001)$. Viral RNA levels in the lung (b, $f$ ), nasal wash (c, g), and brain $(\mathrm{d}, \mathrm{h})(\mathrm{n}=6$ mice per group, two experiments; one-way ANOVA with Dunnett's test with comparison to control mAb: ns, not significant, * $\mathrm{P}<0.05$, ** $\mathrm{P}<$ $0.01, \star \star \star P<0.001, * \star \star \star P<0.0001)$. Dotted line indicates the limit of detection of the assay.

\section{Supplementary Files}

This is a list of supplementary files associated with this preprint. Click to download.

- EDF1neut418b.pdf

- EDF2420.pdf

- EDF3Plaqueassays.pdf

- EDF4.pdf

- EDF5.pdf

- EDF6.pdf

- SupTables1deepsequencing.xlsx

- SuppTableS2sequencing419.xIsx

- TableS3SerummAbconcentrations.xIsx 